\title{
A grands pas sur la voie de la vaccination
}

\section{Yvonne Gilli}

Dr méd., présidente de la FMH

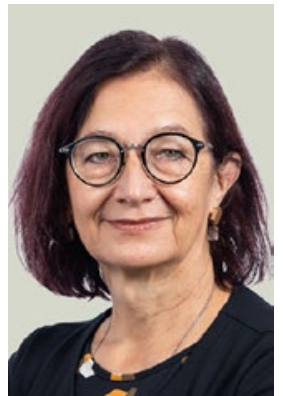

Une étape importante de l'histoire de la médecine a été franchie en 1796 lorsque le Dr Edward Jenner inocula de la variole de vache à un jeune garçon, l'immunisant ainsi contre la variole, une maladie qui sévissait déjà à l'époque des anciens Egyptiens. Depuis, les vaccins ont permis de sauver des millions de vies, en empêchant le développement de diverses maladies ainsi que leurs séquelles. Mais ce n'est qu'en 1980 que la variole a été définitivement éradiquée suite à un programme de l'OMS garantissant une administration coordonnée du vaccin.

La crise du coronavirus montre à quel point tout s'est accéléré dans le monde et je ne parle pas uniquement de la circulation du virus, mais aussi de la diffusion globalisée des connaissances scientifiques. En Suisse, il aura fallu à peine 10 mois pour passer du premier cas d'infection déclaré au Covid-19 [1] à l'approbation et à la mise sur le marché d'un vaccin à ARN messager [2]. Malgré l'immense défi logistique et certaines difficultés, il a été possible au 14 février 2021 d'administrer 542196 doses de vaccin. De plus en plus de patients à risque seront protégés sans devoir s'isoler. La disposition à se faire vacciner est grande et continue de croître, comme l'espoir de mettre fin à la pandémie.

Pourtant, tout le monde ne voit pas cette évolution rapide d'un bon œil. Nombre de personnes se sentent désécurisées. De fausses informations ou des informations qui, privées de contexte, s'avèrent trompeuses se répandent notamment sur les réseaux sociaux offrant une visibilité disproportionnée à de nombreux groupes minoritaires. Cela contribue à envenimer le débat et mène facilement à l'indifférenciation et à la polarisation. La pression morale et le jugement ne doivent pas se substituer aux débats objectifs et pondérés. La médecine ne doit pas non plus se laisser instrumentaliser par ce scénario du «bien» contre le «mal». La principale tâche du médecin est de mettre à disposition des patients des informations spécialisées et de les évaluer en fonction de la situation individuelle de chacun.

Il va de soi qu'en tant qu'organisation professionnelle des médecins, la FMH salue la vaccination comme un nouvel élément de la lutte contre la pandémie de Covid-19 et qu'elle ait assuré son soutien actif dès le dé- but [3]. Si la disposition des médecins à se faire vacciner est très supérieure à la moyenne, il n'en reste pas moins que chaque personne est libre de rendre sa vaccination publique ou non. Dans le cadre de la vaccination contre le Covid-19, il ne s'agit pas de nous mais de nos patientes et patients, c'est primordial pour notre rôle en tant que médecin. Notre mission n'est pas de leur «inoculer» notre opinion, mais de leur transmettre les informations dont nous disposons de manière claire et compréhensible pour qu'ils puissent prendre leur décision de manière éclairée. Au vu des connaissances actuelles quant aux bénéfices et aux risques, il est fort probable que leur décision soit le plus souvent favorable à la vaccination, c'est d'ailleurs ce que montre le nombre croissant de personnes prêtes à se faire vacciner. D'autres patientes et patients en revanche auront leurs raisons d'être contre le vaccin et ce n'est pas à nous d'en juger. L'éthique médicale implique de respecter le libre choix du patient. Demander à quelqu'un de rendre publique sa vaccination va à l'encontre de la protection des droits de la personnalité. Personne p. ex. ne souhaiterait devoir annoncer les contre-indications médicales l'empêchant de se faire vacciner afin d'éviter un jugement moral.

Jusqu'à présent, nous avançons à grands pas sur la voie de la vaccination, grâce aussi à la science, qui a préparé le terrain. En tant que médecin, notre rôle consiste à expliquer à nos patients ce que cette voie signifie pour eux, sans pour autant les y pousser. Aujourd'hui, si l'on parvient à améliorer la disponibilité et la distribution des vaccins au niveau tant national qu'international, et à adapter suffisamment vite les vaccins aux variants, le monde pourrait espérer être impacté beaucoup moins longtemps par le Covid-19 qu'il ne l'a été par de précédentes maladies infectieuses.

\section{Références}

1 Communiqué de presse de l'OFSP, 25 février 2020. Nouveau coronavirus COVID-19: premier cas confirmé en Suisse. www.bag.admin. ch/bag/fr/home/das-bag/aktuell/medienmitteilungen. msg-id-78233.html

2 Communiqué de presse de Swissmedic, 19 décembre 2020. Swiss medic autorise le premier vaccin contre le Covid-19 en Suisse. www.swissmedic.ch/swissmedic/fr/home/news/coronaviruscovid-19/covid-19-impfstoff_erstzulassung.html

3 Communiqué de presse de la FMH, 13 janvier 2021. La FMH soutient la vaccination contre le COVID-19. 